\title{
Optimization of Plate Frame Evaporator for a Standard Vapor Compression Cycle
}

\author{
John R. Simon III, Todd M. Bandhauer \\ Interdisciplinary Thermal Science Laboratory, Colorado State University, Fort Collins, CO 80524, \\ USA
}

\begin{abstract}
:
Vapor compression chillers are the primary cooling technology for large building applications. Chillers have a large up front capital cost, with the heat exchangers accounting for the majority of the cost. Heat exchanger cost is a function of size, and, therefore, a reduction in heat exchanger size can be correlated to a reduction in chiller capital cost. This investigation focuses on the optimization of the evaporator in a vapor compression chiller. To reduce the size and cost of the system, this study utilizes plate and frame heat exchangers in the chiller design, rather than traditional shell and tube. A heat exchanger model was integrated into a simple vapor compression cycle model to determine the relationship between core volume and refrigerant side pressure drop, in an effort to determine the minimum required volume for the evaporator. The model was run in both parallel and counter flow configurations. The heat exchanger model used in this investigation was developed and validated in a previous study for a liquid-coupled evaporator in an experimental vapor compression system. This model accounted for variable fluid properties, and complex geometries within the evaporator core. The minimum volume was achieved by varying the ratio between core length and number of channels, for a fixed evaporator heat duty and outlet condition. This allowed for the inlet condition to float, and be defined by the pressure drop through the core. It was found that there was an optimum relationship between evaporator pressure drop and core volume, and that the parallel flow arrangement resulted in a smaller volume than the counter flow arrangement.
\end{abstract}

Keywords: Evaporation, Plate Heat Exchangers, Two-phase heat transfer, optimization

\section{Introduction:}

Vapor compression cooling systems (VCC) are a significant fraction of the total electrical consumption in industrial, commercial, and residential buildings. Many investigations focus on cycle state point performance optimization, but there is a lack of studies which focus on heat exchanger size optimization [1-3]. Minimizing the size of the heat exchanges in the VCC systems can reduce volume and overall system cost.

Traditionally, large VCC systems use shell and tube evaporators. This type of heat exchanger has a low surface area to volume ratio, which translates to a large spatial footprint. Plate frame heat exchangers are more compact, with a much larger surface area to volume ratio. As shown in Figure 1, plate frame heat exchanger core consists of stacked corrugated stainless steel plates that are compressed together with rubber gaskets to seal the alternating fluid streams.

Advanced configurations of a vapor compression system could use this compact heat exchanger type to reduce system size and overall system cost. Since the heat exchangers account for the majority of the volume and cost of a VCC [4], there is a desire to

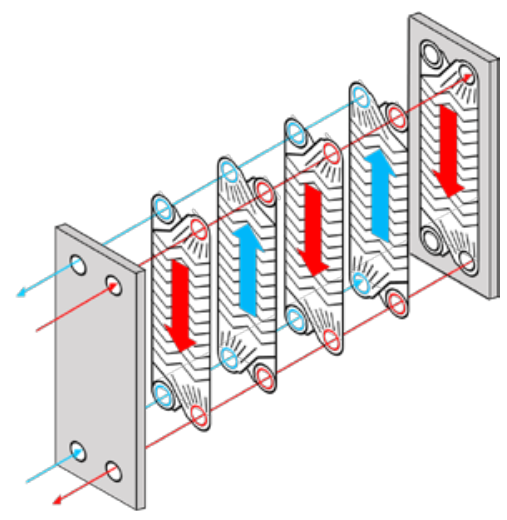

Figure 1: Exploded view of a gasketed plate and frame heat exchanger. 
reduce the size of a unit for the same performance. This study looks take previously validated performance models to minimize the evaporator footprint while maintaining the vapor compression cycle performance. In the following sections, the heat exchanger and cycle modeling method are described briefly, then the optimization process and modeling results are described.

\section{Plate Frame Heat Exchanger Model:}

The plate frame heat exchanger model was developed in a previous investigation, Simon and Bandhauer [5]. The model was developed using a discretization and thermal resistance network method. The investigation compared empirical correlations found in the literature to experimental data. It was found that the Cooper [6] boiling heat transfer correlation in corrugated plate heat exchangers most accurately predicted the data. The Cooper correlation was originally developed for pool boiling, which was also considered valid for use in low mass flux plate frame evaporators by Longo and Gasparella [7]. In addition, the best single phase refrigerant heat transfer correlation was developed by Maslov and Kovalenko [9]. Muley's [10] single phase heat transfer correlation was used for the water glycol side. The heat transfer for the plate frame heat exchanger was modeled to a mean absolute error equal to 7.9\%. Although not validated due to high experimental uncertainties, the Huang et al. [8] two-phase boiling pressure loss correlation was also used to determine the refrigerant pressure loss.

\section{Cycle Modeling Approach:}

The goal of this investigation was to determine the optimum size and configuration of a plate frame evaporator in a vapor compression cycle. This section elaborates on the methods and assumptions used in the cycle modeling and the accompanying evaporator optimization approach. The refrigerant pressure loss was used as the optimization parameter for the evaporator size within a simple vapor compression cycle. As shown in Figure 2, the cycle consists of four components: compressor, condenser, expansion valve, and evaporator. The pressure loss through the condenser was neglected in this simulation and the refrigerant at the outlet of the evaporator was a saturated vapor. State points one, two, and four from Figure 2 were fixed

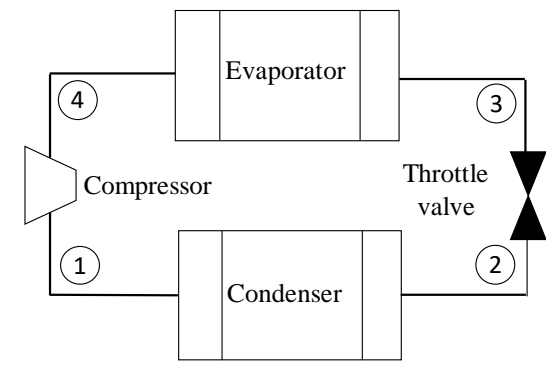

Figure 2: Schematic of a simple vapor compression cycle. in the model, so that the compressor and condenser performance were not affected by the changing evaporator conditions. Point three was varied depending on the evaporator pressure loss and, thus, the expansion valve will accommodate the remaining amount of pressure not lost through the evaporator. It was assumed that this change in pressure does not affect the expansion valve size. Further, the thermodynamic coefficient of performance was set to 5 and the compressor isentropic efficiency was set to 0.675 . The throttling valve was assumed to be isenthalpic. The pressure loss and heat transfer through the system piping was assumed negligible. The input parameters are listed in Table 1.

The thermodynamics of the evaporator were modeled first. The coolant was a $70 / 30$ by volume mixture of water and propylene glycol. The water-glycol inlet and outlet temperature were set to $12^{\circ} \mathrm{C}$ and $7^{\circ} \mathrm{C}$, respectively, which are standard for space conditioning applications. The water glycol flow rate was fixed to $16 \mathrm{~kg} \mathrm{~s}^{-1}$ thereby setting the heat duty of the cycle to $305.8 \mathrm{~kW}$. All heat transfer occurred while the refrigerant was a twophase mixture, since the outlet was fixed as a saturated vapor. The energy decrease of the water-glycol was set equal to the energy increase of the refrigerant. The enthalpy at the heat exchanger inlet is set via the outlet enthalpy of the expansion valve, state point 3. The exiting enthalpy was determined using the saturation condition at the outlet temperature of the evaporator. The inlet and outlet conditions as well as the flow rates were used as the boundary conditions for the heat exchanger model. 
Table 1: Cycle Condition

\begin{tabular}{ll}
\hline COP & 5 \\
\hline $\begin{array}{l}\text { Refrigerant Mass Flow } \\
\text { Rate [kg s }\end{array}$ & 2.27 \\
\hline $\begin{array}{l}\text { Evaporator Water-Glycol } \\
\text { Mass Flow Rate [kg s' }\end{array}$ & 16 \\
\hline $\begin{array}{l}\text { Condenser Water-Glycol } \\
\text { Mass Flow Rate [kg s' }\end{array}$ & 11.9 \\
\hline $\begin{array}{l}\text { Evaporator Water-Glycol } \\
\left.\text { Temperature in, out [ }{ }^{\circ} \mathbf{C}\right]\end{array}$ & 12,7 \\
\hline $\begin{array}{l}\text { Condenser Water-Glycol } \\
\left.\text { Temperature in, out [ }{ }^{\circ} \mathbf{C}\right]\end{array}$ & 29,37 \\
\hline $\begin{array}{l}\text { Compressor Efficiency } \\
\text { Evaporator Duty [kW] }\end{array}$ & $67.5 \%$ \\
\hline Condenser Duty [kW] & 306 \\
\hline
\end{tabular}

After the refrigerant exits the evaporator, it enters the compressor labeled as state point 4 in Figure 2. The compressor isentropic efficiency is set to $67.5 \%$, comparable to commercially available centrifugal compressors. The compressor efficiency, along with the inlet enthalpy, is used to determine the compressor outlet enthalpy. The isentropic enthalpy was calculated using the entropy at state 4 and the pressure at state 1 . The high side pressure at state 1 was determined from the condenser.

The condenser was a liquid coupled heat exchanger and used a coolant loop of 70/30 by volume water propylene glycol mixture. The inlet and outlet temperatures were set for the water-glycol side, $29^{\circ} \mathrm{C}$ and $37^{\circ} \mathrm{C}$ respectively. The heat exchanger was split into two regions, super-heated and two phase, requiring two sets of continuity equations. The same type of continuity equations, used for the evaporator were used for each region of the condenser. Finally the refrigerant passes through the expansion valve. The valve is assumed to be isenthalpic to close the cycle.

\section{Heat Exchanger Optimization Strategy:}

To determine the pressure drop and core volume relationship for the heat exchanger operating in both parallel and counter flow, the heat exchanger model was integrated into the full vapor compression cycle system model. The state points at 3 and 4 were entered as boundary conditions to the heat exchanger model which calculated the length, and depth of the required core size.

The water-glycol side boundary conditions were set and held constant throughout the optimization. The outlet of the refrigerant was also set, leaving the inlet, state 3 to be varied. State 3 was varied to account for the pressure drop through the core by changing the number of channel sets, thus decreasing the core depth. To accommodate the required heat transfer area, the length of the plate frame core subsequently increases. As the pressure drops were parametrically tested for each core configuration, the core volume was calculated to determine the configuration and pressure drop that resulted in the smallest volume.

\section{Results and Discussion:}

It was theorized that an optimum amount of pressure loss in the evaporator would lead to a minimum amount of evaporator core volume. The plate frame heat exchanger model was used to size a core for a fixed refrigerant outlet temperature over a range of pressure drops, in both parallel and counter flow configuration. As shown in Figure 3, the core volume decreases with increasing pressure drop at low pressure drops. At high pressure drop, the core volume increases. As the number of plates are reduced, the mass flux and pressure drop both increase. This leads to an increase in the overall heat transfer coefficient for both working fluids. As a competing effect, the entering temperature difference between the two fluids decrease as a function of increasing pressure drop, which increased the required heat transfer area and the core volume. This became more prevalent at higher pressure drops with fewer plates. At low pressure drops the effect of increasing heat transfer coefficient dominates over the effect of reduced thermal driving potential, which led to an inverse relationship between volume and pressure drop. At $5 \mathrm{kPa}$ pressure drop in the counter flow configuration and $15 \mathrm{kPa}$ pressure drop in the parallel flow configuration, the effect of 
the two trends are equally balanced resulting in an inflection point. After this point the reduced thermal driving potential dominates, increasing volume with increasing pressure drop.

The trends described above were observed in both parallel and counter flow cases. The counter flow arrangement had an overall optimum volume of $1.73 \mathrm{~m}^{3}$, larger than that of the parallel flow arrangement minimum at $1.34 \mathrm{~m}^{3}$. This is counter intuitive when thinking about single phase heat exchangers, where the counter flow arrangement will have a large log mean temperature difference, leading to a smaller core volume than a parallel flow case. However, because of the saturation temperature drop through the evaporator core due to the refrigerant pressure drop, the parallel flow heat exchanger resulted in a larger log mean temperature difference than the counter flow configuration.

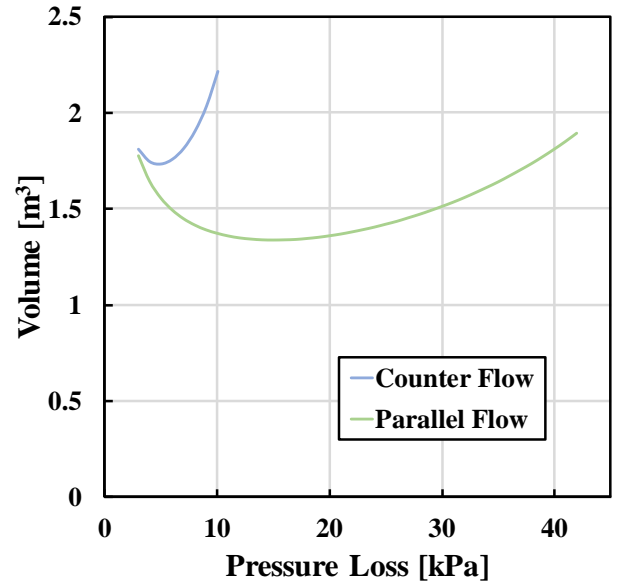

Figure 3: Relationship between evaporator volume and the pressure loss

\section{Conclusion:}

The present investigation utilized a high fidelity heat exchanger sizing model to determine the minimum volume required for a vapor compression evaporator. The model was developed to size the core of a gasketed plate and frame evaporator. A simple vapor compression cycle was modeled to determine the boundary conditions of the evaporator. All cycle state points remained constant except the evaporator inlet to allow for a constant compressor and condenser design. The minimum volume occurred in the parallel flow arrangement due to the saturation temperature decrease of the refrigerant in the two-phase flow region. The parallel flow arrangement in this investigation had a larger log mean temperature difference leading to a smaller required volume.

\section{References:}

[1] Selbas, R., Kizilkan, O., and Sencan, A., 2006, “Thermeconomic Optimization of Subcooled and Superheated Vapor Compression Refigeration Cycle,” Energy, 31, pp. 2108-2128.

[2] Yee, R. P., and Hermes, C. J. L., 2019, “Thermodynamic Design of a Mesoscale Vapor Compression Cooling Device,” Appl. Therm. Eng.

[3] Pak, T. C., and Ri, Y. C., 2019, “Optimum Designing of the Vapor Compression Heat Pump Using System Using Genetic Algorithm,” Appl. Therm. Eng.

[4] Gibson, S., Young, D., and Bandhauer, T. M., 2017, “Technoeconomic Optimization of Turbocompression Cooling Systems,” Int. Mech. Eng. Congr. Expo.

[5] Simon, J., and T. M. Bandhauer, 2019, " Model Valvidation for Large Evaporative Plate Frame Heat Exchangers", ${ }^{\text {th }}$ ASTFE TFEC, Las Vegas, NV, USA, paper TFEC-2019-28122.

[6] Cooper, M. G., 1984, "Heat Flow Rates in Saturated Nucleate Pool Boiling-A Wide-Ranging Examination Using Reduced Properties,” Adv. Heat Transf.

[7] Longo, G. A., and Gasparella, A., 2007, "Refrigerant R134a Vaporisation Heat Transfer and Pressure Drop inside a Small Brazed Plate Heat Exchanger,” Int. J. Refrig.

[8] Huang, J., Sheer, T. J., and Bailey-Mcewan, M., 2012, "Heat Transfer and Pressure Drop in Plate Heat Exchanger Refrigerant Evaporators,” International Journal of Refrigeration.

[9] Maslov, A., and Kovalenko, L., 1972, "Hydraulic Resistance and Heat Transfer in Plate Heat Exchangers,” Molochnaya Promyshlenflost, 10, pp. 20-22.

[10] Muley, A., 1997, “Heat Transfer and Pressure Drop in Plate Heat Exchangers,” University of Cincinnati. 